OLIVEIRA, C.M.; SOUZA, R.J.; YURI, J.E.; MOTA, J.H.; RESENDE, G.M. Época de colheita e potencial de armazenamento em cultivares de alho. Horticultura Brasileira, Brasília, v.22, n.4, p.804-807, out-dez 2004.

\title{
Época de colheita e potencial de armazenamento em cultivares de alho
}

Carlos Manoel de Oliveira'; Rovilson J. de Souza² ${ }^{2}$ Jony E. Yuri³ ${ }^{3}$ José H. Mota ${ }^{4}$; Geraldo M. de Resende

${ }^{1}$ FIAP, Depto. Ciências Biológicas, Av. Amazonas, 777, 38180-000 Araxá-MG; ${ }^{2}$ UFLA, DAG, C. Postal 37, 37200-000 Lavras-MG; ${ }^{3}$ REFRICON, Rod. Régis Bittencourt s/n, km 294, 06850-000 Itapecerica da Serra-SP; E-mail: jonyyuri@uol.com.br; ${ }^{4}$ UFMS, Depto. Ciências Agrárias, C. Postal 533, 79804-970 Dourados-MS; ${ }^{5}$ Embrapa Semi-Árido, C. Postal 23, 56300-000 Petrolina-PE.

\section{RESUMO}

o potencial de armazenamento de quatro cultivares de alho, colhidos em diferentes épocas com e sem toalete, foi avaliado em experimento conduzido em galpão de armazenamento da Universidade Federal de Lavras (MG). Avaliou-se a perda de massa e o índice de chochamento dos bubos plantas. As perdas de massa ao final do armazenamento foram reduzidas à medida que se colheram bulbos mais desenvolvidos, em estádio avançado de maturação sendo que os bulbos armazenados sem a prática de toalete apresentaram menor porcentagem de bulbilhos chochos ao final de 180 dias de armazenamento.

Palavras-chave: Allium sativum L., perda de massa, chochamento de dentes, armazenamento.

\section{ABSTRACT}

\section{Harvest date and storage potential in garlic cultivars.}

The storage potential of four garlic cultivars, harvested on different dates with or without toilet, was determined in an experiment conducted in a warehouse, in Lavras, Minas Gerais State, Brazil. The mass loss and index of shrunken bulbs were evaluated. Mass loss at the final of storage period was lesser when bulbs were harvested at a more advanced maturation stage and, the bulbs stored without the toilet practice presented lesser empty bulblets at the end of 180-day storage.

Keywords: Allium sativum L., mass loss, shrunken bulbs, storage.

\section{(Recebido para publicação em 15 de maio de 2003 e aceito em 23 de março de 2004)}

$\mathrm{O}$ Brasil é um dos países que mais consome alho, a maior parte comercializado no mercado ao natural, ainda que o consumo de pastas e outros produtos processados de alho venha crescendo gradativamente. A produção nacional de alho, no ano de 2001, foi de aproximadamente 102.150 toneladas, o que representou $1,01 \%$ da produção mundial, de 10,121 milhões de toneladas. Essa quantidade coloca o país como o oitavo maior produtor mundial de alho (Agrianual, 2003). No entanto, essa produção, não é suficiente para atender a nossa demanda, bem como não atende satisfatoriamente as exigências de qualidade do nosso mercado consumidor. A importação de alho, principalmente da Argentina, completa nossa necessidade interna de consumo. A Argentina apresenta condições edafoclimáticas bem mais favoráveis e custo da produção menor que o apresentado pelo Brasil. Alguns produtores nacionais, antecipam a colheita e a cura, comercializando sua produção fora do pico de safra e com isso obtendo melhores preços.

O ponto de colheita é fator importante no processo agrícola, sendo que sua determinação permite um melhor aproveitamento do produto vegetal com mínimo de perdas e com qualidade (Puiatti, 1982). Esta relaciona-se ao conjunto de atributos ou propriedades que tornam produtos agrícolas apreciados como alimento. Esses atributos, por sua vez, dependem do destino: armazenamento, consumo ao natural ou processamento (Chitarra, 1994).

Após a colheita, para manter a qualidade do alho e possibilitar o armazenamento em condições adequadas, é importante que se proceda a cura dos bulbos, isto é, a perda de água até um ponto adequado. $\mathrm{O}$ processo, em geral consiste primeiramente na secagem do alho no campo, protegido do sol, pelas suas folhas, por dois a três dias, (pré-cura a campo), seguida de secagem a sombra por um período de 20 a 50 dias (cura a galpão). Segundo Souza (1981), a melhor cura é a de 60 dias, o que confere maior conservação dos bulbos durante o armazenamento.

$\mathrm{O}$ armazenamento, em condições atmosféricas é muito utilizado, para as culturas da cebola e do alho permitindo aos produtores a comercialização escalonada do produto. Segundo Carvalho (1991), durante o armazenamento de alho ocorrem perdas de massa e alterações na composição físico-química dos bulbos, estando estas alterações relacionadas à transpiração, à atividade respiratória, ao brotamento, às infecções microbianas e ao ataque de pragas na fase pós-colheita na cura e no armazenamento. Bulbos de alho com elevado teor de água perdem maior porcentagem de peso do que aqueles com menor teor de água. No início da fase de cura pós-colheita de bulbos, ocorre maior perda de massa, a qual diminui gradualmente com o decorrer do armazenamento em alho bem conservado (Finger e Puiatti, 1994; Vieira, 1989). Outro indicador da capacidade de conservação de alho é o grau de chochamento. De modo geral, as cultivares com menor número de bulbilhos por bulbo perdem maior quantidade de bulbilhos por chochamento (Campos, 1979). Segundo Luengo et al. (1996), o chochamento parcial ou total de bulbos é considerado um dos defeitos mais graves apontados pelas portarias ministeriais, sendo $15 \%$ o máximo permitido como limite para que o lote seja considerado do tipo comercial.

O objetivo deste trabalho foi avaliar quatro cultivares de alho em cultivo sem vernalização, consideradas como seminobres quanto à capacidade de armazenamento relacionada a diferentes datas de colheita.

\section{MATERIAL E MÉTODOS}

O experimento foi conduzido na área experimental da Universidade Federal de Lavras (MG), a 918 m de altitude, 
latitude $21^{\circ} 14^{\prime} \mathrm{S}$ e longiitude $45^{\circ} 00^{\prime}$ W GRW (Castro Neto et al., 1980). O clima da região é do tipo Cwa com características de $\mathrm{Cwb}$, apresentando duas estações definidas: seca (abril a setembro) e chuvosa (outubro a março), segundo a classificação climática de Köppen.

Os alhos utilizados neste trabalho foram obtidos de um experimento plantado em abril de 1.998, em delineamento em blocos ao acaso com 20 tratamentos, sendo cinco épocas de colheita $(134 ; 141$; 148; 155 e 162 dias) e quatro cultivares, colhendo-se 20 plantas por parcela. As cultivares apresentaram ciclo de 5-6 meses sendo caracterizadas como pertencentes ao ciclo médio de acordo com Souza et al. (2002). Com o intuito de avaliar o período de armazenamento das cultivares de alho foi montado o experimento em delineamento em blocos casualizados em um esquema fatorial $5 \times 4 \times 2$, onde avaliou-se 5 épocas de colheitas [(134; 141; 148; 155 e 162 dias após o plantio (dap)] e 4 cultivares de alho (Gigante de Curitibanos, Gravatá, Gigante Roxo e Gigante de Lavínia) com e sem toalete. Após a colheita as parcelas foram submetidas a uma pré-cura ao sol, durante 5 dias, em terreiro cimentado coberto, onde as folhagem das plantas cobriam os bulbos, cuidando-se para que o sol não queimasse os bulbilhos. Após a pré-cura as parcelas foram subdividas em duas, onde procedeu-se as pesagens iniciais e no final dos 180 dias de armazenamento, para estudar-se o efeito da presença e ausência das folhas e raízes na perda de massa e no índice de chochamento do alho armazenado sendo os dados expressos em percentagens. As subparcelas com toalete (corte das raízes e das folhas aos $2 \mathrm{~cm}$ ) e sem toalete constaram de 10 plantas cada, acondicionadas em sacos telados.

Para avaliar o índice de chochamento, ao final dos 180 dias de armazenamento, os bulbos de alho foram debulhados e procedeu-se a contagem dos bulbilhos chochos, sendo expresso em porcentagem do número total de bulbilhos de cada subparcela. Os dados foram submetidos à análise de variância, ao nível de 5\% de probabilidade.

\section{RESULTADOS E DISCUSSÃO}

Houve efeito significativo tanto para perda de massa (\%) como para índice

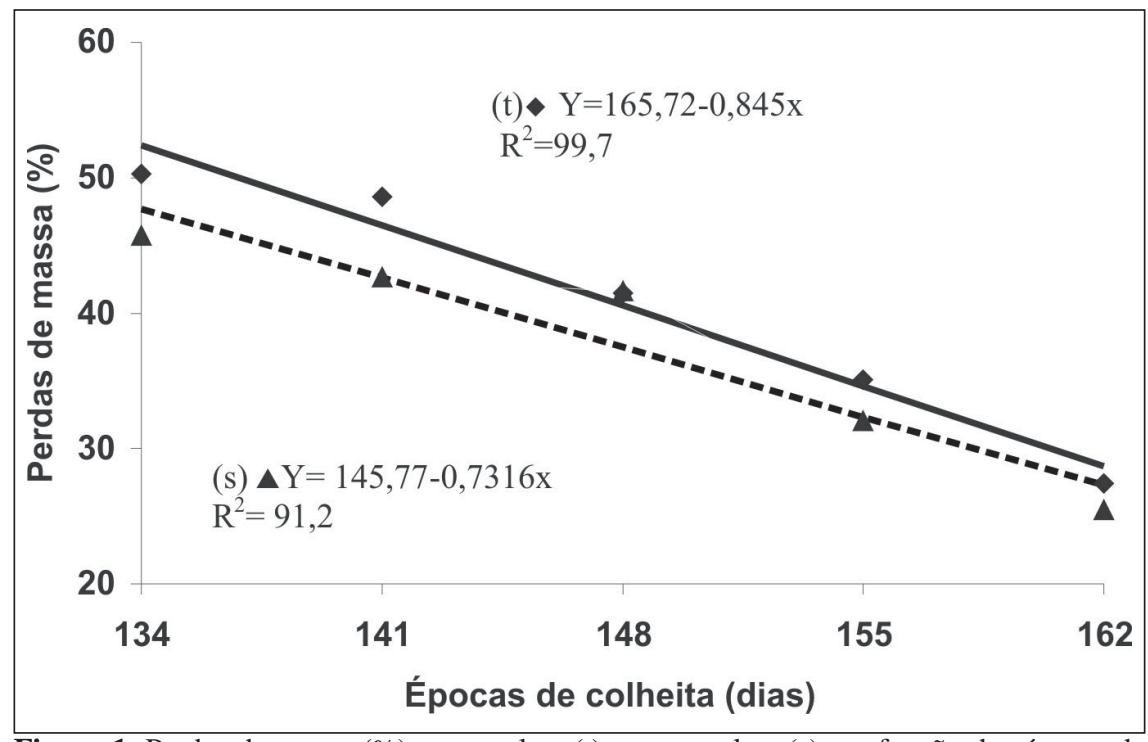

Figura 1. Perdas de massa (\%) com toalete (t) e sem toalete (s) em função das épocas de colheita (dias após o plantio). Lavras (MG), UFLA, 1999.

Tabela 1. Valores médios para perdas de massa (\%) em função das épocas de colheita e das cultivares. Lavras UFLA, 1999.

\begin{tabular}{|c|c|c|c|c|c|}
\hline \multirow{2}{*}{$\begin{array}{l}\text { Épocas de } \\
\text { colheita com } \\
\text { toalete (dap*) }\end{array}$} & \multicolumn{5}{|c|}{ Cultivares } \\
\hline & $\begin{array}{c}\text { Gigante } \\
\text { Curitibanos }\end{array}$ & Gravatá & $\begin{array}{l}\text { Gigante } \\
\text { Lavínia }\end{array}$ & $\begin{array}{c}\text { Gigante } \\
\text { Roxo }\end{array}$ & Médias \\
\hline 134 & $44,81 \mathrm{aB}$ & $46,95 \mathrm{aAB}$ & 51,21 aA & 48,98 aAB & 47,99 \\
\hline 141 & 45,66 aA & 47,02 aA & $44,99 \mathrm{bA}$ & 44,78 aA & 45,61 \\
\hline 148 & 42,54 aAB & 44,51 aA & 41,29 bcAB & $38,10 \mathrm{bB}$ & 41,61 \\
\hline 155 & $32,45 \mathrm{Bb}$ & 34,05 bB & $37,87 \mathrm{~cd} A \mathrm{~B}$ & $29,83 \mathrm{cB}$ & 33,55 \\
\hline 162 & $25,49 \mathrm{cb}$ & $25,00 \mathrm{cB}$ & $35,87 \mathrm{dA}$ & $19,47 \mathrm{dcC}$ & 26,46 \\
\hline Médias & 38,19 & 39,51 & 42,25 & 36,23 & 39,05 \\
\hline
\end{tabular}

Médias seguidas por letras minúsculas nas colunas e médias seguidas por letras maiúsculas nas linhas não diferem entre si a $5 \%$ de probabilidade pelo teste de Tukey; *Dias após plantio

de chochamento (\%). Para perda de massa houve interação significativa para épocas bem como cultivares e toalete dos bulbos, e as interações época x cultivar, época $\mathrm{x}$ toalete, e cultivar $\mathrm{x}$ toalete. O mesmo foi observado para índice de chochamento de bulbos com interações para épocas, cultivar e toalete e as interações época x cultivar, época $\mathrm{x}$ toalete e cultivar $\mathrm{x}$ toalete.

A época de colheita interferiu estatisticamente nos resultados de perda de massa, para bulbos com e sem toalete apresentando uma regressão linear decrescente, em que as maiores perdas foram verificadas em colheitas com os bulbos de alho ainda verdes (134 dias) e as menores perdas ocorreram na colheita mais tardia (162 dias) (Figura 1). Essa diferença de perda de massa para bulbos com e sem toalete correspondeu a $23,66 \%$ e $20,48 \%$ respectivamente. Comparando-se as perdas de peso entre bulbos com e sem toalete, observou-se que as maiores perdas ocorreram com bulbos sem toalete. Esse fato, segundo Finger e Puiatti (1994) é devido à presença da parte aérea da planta, o que aumenta a superfície de evaporação. Deve-se colher as plantas quando apresentarem sinais de senescência ou maturidade fisiológica e, segundo Luengo et al. (1996), a colheita mais tardia promove aumento no teor de matéria seca, favorecendo o armazenamento, o que é uma característica desejável.

Observou-se (Tabela 1) que a cultivar Gigante de Lavinia, foi a que apresentou a maior porcentagem média de perda de massa aos 134 dias $(51,21 \%)$ e, na última colheita aos 162 dias a que apresentou o menor valor de perda foi a 


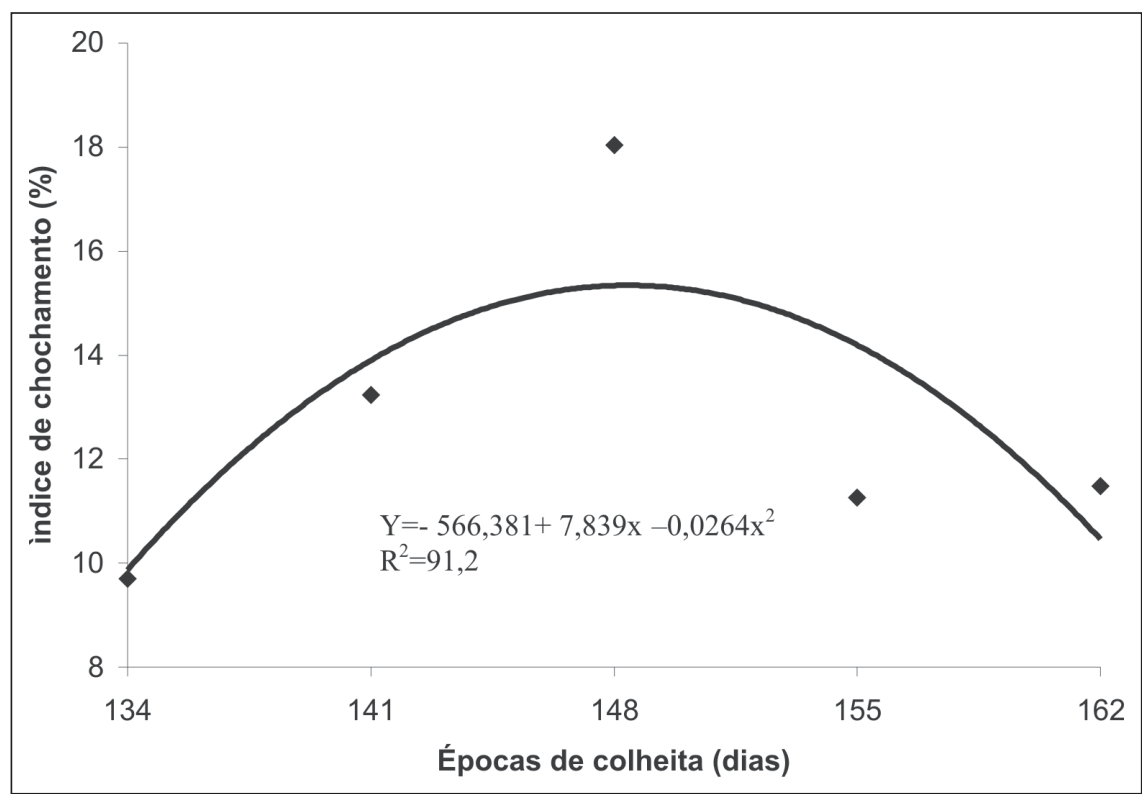

Figura 2. Índice de chochamento (\%) em função das épocas de colheita (dias após o plantio). Lavras (MG), UFLA, 1999.

Tabela 2. Valores médios para perdas de massa (\%) em função de cultivares e dos tratamentos com e sem toaletes. Lavras (MG), UFLA, 1999.

\begin{tabular}{lcc}
\hline \multirow{2}{*}{ Cultivares } & \multicolumn{2}{c}{ Tratamentos } \\
\cline { 2 - 3 } & Com toalete & Sem toalete \\
\hline Gigante Curitibanos & 38,19 a A & 38,24 b A \\
Gravatá & 37,86 a B & 41,16 b A \\
Gigante Lavínia & 40,19 a B & 44,30 a A \\
Gigante Roxo & 33,77 b B & 38,77 b A \\
\hline Média & 35,50 & 40,61 \\
\hline
\end{tabular}

Médias seguidas por letras minúsculas iguais nas colunas e maiúsculas nas linhas não diferem entre si a $5 \%$ de probabilidade pelo teste de Tukey.

Tabela 3. Valores médios para índice de chochamento (\%) em bulbos armazenados, sem e com a prática de toalete em função das épocas de colheita e das cultivares. Lavras (MG), UFLA, 1999.

\begin{tabular}{lccccc}
\hline $\begin{array}{l}\text { Épocas de } \\
\text { colheita (dap*) }\end{array}$ & $\begin{array}{c}\text { Gigante } \\
\text { Curitibanos }\end{array}$ & Gravatá & $\begin{array}{c}\text { Gigante } \\
\text { Lavínia }\end{array}$ & $\begin{array}{c}\text { Gigante } \\
\text { Roxo }\end{array}$ & Médias \\
\hline \multicolumn{5}{c}{ Sem toalete } \\
\hline 134 & $3,59 \mathrm{aA}$ & $9,79 \mathrm{aA}$ & $4,74 \mathrm{aA}$ & $3,68 \mathrm{aA}$ & 5,45 \\
141 & $5,86 \mathrm{aA}$ & $6,78 \mathrm{aA}$ & $4,96 \mathrm{aA}$ & $7,02 \mathrm{aA}$ & 6,16 \\
148 & $4,47 \mathrm{aA}$ & $4,27 \mathrm{aA}$ & $1,36 \mathrm{aA}$ & $2,89 \mathrm{aA}$ & 3,25 \\
155 & $5,06 \mathrm{aA}$ & $6,57 \mathrm{aA}$ & $3,26 \mathrm{aA}$ & $3,95 \mathrm{aA}$ & 4,71 \\
162 & $7,95 \mathrm{aA}$ & $3,82 \mathrm{aA}$ & $2,04 \mathrm{aA}$ & $2,84 \mathrm{aA}$ & 4,19 \\
\hline Médias & 5,39 & 6,25 & 3,27 & 4,10 & 4,75 \\
\hline \multicolumn{5}{c}{ Com toalete } \\
134 & $11,89 \mathrm{aB}$ & $6,40 \mathrm{aB}$ & $6,69 \mathrm{aA}$ & $13,93 \mathrm{aA}$ & 9,73 \\
141 & $22,93 \mathrm{aA}$ & $11,12 \mathrm{bB}$ & $10,38 \mathrm{bA}$ & $8,60 \mathrm{bA}$ & 13,26 \\
158 & $20,86 \mathrm{ab} \mathrm{AB}$ & $30,16 \mathrm{aA}$ & $8,91 \mathrm{cA}$ & $12,26 \mathrm{bcA}$ & 18,05 \\
162 & $17,57 \mathrm{aAB}$ & $8,77 \mathrm{aB}$ & $10,40 \mathrm{aA}$ & $8,22 \mathrm{aA}$ & 11,24 \\
\hline Médias & $13,60 \mathrm{abAB}$ & 12,36 abB & $15,21 \mathrm{aA}$ & $4,84 \mathrm{bA}$ & 11,50 \\
\hline
\end{tabular}

Médias seguidas por letras minúsculas iguais nas colunas e maiúsculas nas linhas não diferem entre si a $5 \%$ de probabilidade pelo teste de Tukey; *Dias após plantio cultivar Gigante Roxo com 19,47\%, provavelmente por apresentar túnicas externas mais íntegras e menos permeáveis, que dificultam as trocas gasosas em forma de vapor (Campos, 1979). A cultivar Gigante de Lavínia foi a que apresentou a maior percentagem média de perda de massa $(42,25 \%)$. Peixoto e Filgueira (1983) também obtiveram elevado índice de perda de massa para a cultivar Gigante de Lavínia que se destacou aos 180 dias de armazenamento, com 58\% de perdas.

No armazenamento de bulbos toaletados, os percentuais em perda de massa foram mais baixos (média de $35,50 \%$ ) comparados às perdas de massa em bulbos sem o toalete (média de $40,61 \%$ ). Sem a parte aérea das plantas há menores perdas, ou seja, a folhagem influi negativamente para o aumento das perdas devido à perda de água pelas folhas (Finger e Puiatti, 1994). Com a prática de toalete, a cultivar Gigante Roxo apresentou menor percentual médio de perda de massa $(33,77 \%)$, sendo que as cultivares Gigante Curitibanos, Gravatá e Gigante de Lavinia não apresentaram diferenças estatísticas entre si, com $38,19,37,86$ e $40,19 \%$ de perda de massa, respectivamente. (Tabela 2).

O ponto de colheita apresentou influência no índice de chochamento das cultivares estudadas. Verificou-se entre as diferentes épocas de colheita, uma regressão quadrática $(\mathrm{Y}=-566,381+$ $\left.7,8392 x-0,0264 x^{2}, r^{2}=0,91\right)$, onde o menor índice de chochamento foi obtido aos 134 dias $(10,03 \%)$ com toalete e o maior índice foi de $15,55 \%$ de bulbos chochos aos 148 dias com toalete. A partir desta data, os índices declinaram, chegando a um valor de 10,72\% aos 162 dias (Figura 2).

Quando os bulbos foram armazenados sem a prática de toalete, observouse uma substancial redução na porcentagem de chochamento, em relação aos bulbos toaletados (Tabela 3), sendo os valores médios de 4,75\% (Gigante Curitibanos: 5,39; Gravatá: 6,25; Gigante Lavínia: 3,27 e Gigante Roxo: 4,10) e $12,76 \%$, respectivamente. Uma das prováveis causas para a redução desses índices foi a dificuldade de penetração das pragas nos bulbos não toaletados, já que estas cultivares, em regiões quen- 
tes, são muito próprias a elas. Outra provável causa é que mesmo após a colheita há ainda transferência de sólidos solúveis das folhas para os bulbos, o que pode favorecer a conservação pós-colheita havendo até aumento de peso dos bulbos durante a cura. Resultados encontrados pelo ITAL (1977), também mostram diferentes índices de chochamento para alho não toaletado, com oscilações de 5,43 a 16,47\% para diversas cultivares aos 154 dias de armazenamento.

Quando o armazenamento foi efetuado com os bulbos toaletados, tanto para as épocas de colheita, como para as cultivares, a porcentagem de bulbos chochos foi alta, chegando a uma média de $12,76 \%$ contra $4,75 \%$ nos não toaletados (Tabela 4).

Diante disto, nas condições em que se realizou o experimento, conclui-se que a colheita de alho verde apresentou as maiores porcentagens de perda de massa e um alto índice de chochamento dos bulbos armazenados. Assim, a co- lheita deve ocorrer quando os bulbos apresentarem ponto de maturidade fisiológico adequado que varia com a cultivar. $\mathrm{O}$ armazenamento dos bulbos sem a prática do toalete foi determinante para a redução da porcentagem de bulbilhos chochos durante o armazenamento.

\section{LITERATURA CITADA}

AGRIANUAL 2003. Anuário da Agricultura Brasileira. São Paulo. FNP Consultoria \& Comercio, 2002.543 p

CAMPOS, T.G.S. Conservação de seis cultivares de alho em relação aos teores de boro, cálcio, fósforo, magnésio, e enxofre e as características morfológicas de bulbos e bulbilhos. 1979. 38 p. (Tese mestrado) UFV, Viçosa.

CARVALHO, V.D. Tempo de armazenamento na qualidade do alho, $\mathrm{Cv}$ Amarante. Pesquisa Agropecuária Brasileira, Brasília, v.26, n.10, p.1679-1684, 1991.

CASTRO NETO, P.; SEDIYAMA, G.C.; VILELA, E.A. Probabilidade de ocorrência de períodos secos em Lavras, MG. Ciência e Prática, Lavras, v.4, n.1, p.45-55, 1980

CHITARRA, M.I.F. Colheita e qualidade pós colheita de frutos. Informe Agropecuário, Belo horizonte, v.17, n.179, p.8-18, 1994.
FINGER, F.L.; PUIATTI, M. Efeito da época da toalete sobre a cura e o armazenamento de bulbos de alho. Horticultura Brasileira, Brasília, v.12, n.2, p.166-168, 1994.

ITAL. Armazenamento de variedades de alho (Allium sativum L.) mais comercializadas. Campinas: ITAL, 1977, 37 p. (Relatório Final, C07/77). LUENGO, R.F.A.; MENEZES SOBRINHO, J.A.; SILVA, J.L.O. Chochamento do alho 'Amarante" durante o armazenamento em função da época de colheita. Pesquisa Agropecuária Brasileira, Brasília, v.31, n.8, p.581-584, 1996.

PEIXOTO, N.; FILGUEIRA, F.A.R. Efeito de níveis de boro na produção e conservação de alho em Anápolis. Horticultura Brasileira, Brasília, v.1, n.1, p.47-48, 1983.

PUIATTI, M. Fisiologia pós-colheita do inhame (Colocausia esculenta L. schott) In: MÜLLER, J.J.V.; CASALI, V.W.D. (eds.). Seminários de olericultura. Viçosa: UFV, v.6. p.151-175, 1982. SOUZA, R.J. Comportamento de cultivares de alho (Allium sativum $L$.) em diferentes épocas de plantio, na região do Programa de Assentamento Dirigido do Alto Paranaíba (PADAP). 1981. 90 p. (Tese mestrado) UFV, Viçosa, Viçosa.

SOUZA, R.J.; PASQUAL, M.; MACHADO, A.Q.; GONÇALVES, L.D. Cultura do alho. Lavras: UFLA, 2002.90 p. Texto acadêmico.

VIEIRA, G.S. Dormência e conservação pós-colheita do alho (Allium sativum L.) submetido à cura artificial. 1989. 42 p. (Tese mestrado) UFV, Viçosa, Viçosa. 